\title{
Study on Technical Schemes for Major Pollutants Emission Reduction in Beijing North Canal River Basin Based on Watershed Water Quality Target Management
}

\author{
Gang Wang1,2*, Denghua Yan ${ }^{1,2 \#, ~ T a o ~ P a n ~}{ }^{3 \#}$, Xiaoyan He1,2, Jun Qi ${ }^{3 *}$, Minglei Ren ${ }^{1,2}$, Liping Zhao ${ }^{1,2}$, \\ Fan Wang1,2, Zhongbo Zhang1,2, Xiaoming Jiang ${ }^{1,2}$, Xiaodi Fu ${ }^{1,2}$
}

\author{
${ }^{1}$ State Key Laboratory of Simulation and Regulation of Water Cycle in River Basin, China Institute of Water Resources and \\ Hydropower Research, Beijing, China \\ ${ }^{2}$ Research Center on Flood and Drought Disaster Reduction of the Ministry of Water Resources, Beijing, China \\ ${ }^{3}$ Beijing Longtao Environmental Technology Co Ltd., Beijing, China \\ Email: "yandh@iwhr.com, "pantao@longtech-env.com
}

How to cite this paper: Wang, G., Yan, D.H., Pan, T., He, X.Y., Qi, J., Ren, M.L., Zhao, L.P., Wang, F., Zhang, Z.B., Jiang, X.M. and Fu, X.D. (2019) Study on Technical Schemes for Major Pollutants Emission Reduction in Beijing North Canal River Basin Based on Watershed Water Quality Target Management. Journal of Water Resource and Protection, 11, 1327-1350. https://doi.org/10.4236/jwarp.2019.1111077

Received: September 26, 2019

Accepted: November 2, 2019

Published: November 5, 2019

Copyright (อ 2019 by author(s) and Scientific Research Publishing Inc. This work is licensed under the Creative Commons Attribution International License (CC BY 4.0).

http://creativecommons.org/licenses/by/4.0/

\section{c. (i) Open Access}

\begin{abstract}
Water quality target management in watershed is the fundamental choice of city rivers suffering both serious pollution and severe water shortage. In this study, we performed a case study regarding river pollution control plan based on water quality target management in the North Canal River catchment of Beijing section, in order to obtain effective water quality improvement programs. The ammonia nitrogen $\left(\mathrm{NH}_{3}-\mathrm{N}\right)$ and chemical oxygen demand (COD) were taken as the main controlling pollutants. Water quality targets and basic water quality improvement scenarios were set up considering different intensities of population regulation scenarios and gradually strengthening emission control measures. The MIKE11 model was adopted to simulate the effects of a range of water quality improvement scenarios. Results indicated that the basic scenarios could dramatically improve the surface water environment. However, additional intensive and combined measure programs should be implemented to ensure that the water quality would basically meet the targets of corresponding water function zones. The results highlight the need to implement water conservation in water shortage urban river basin and show the importance of enhancing drainage communication and conducting ecological water replenishment in such kind basins. It is expected to provide a reference for the water environment management practice of other metropolis in the world facing both crisis of water resource shortage and water environment pollution.
\end{abstract}

*These authors contributed equally to this work. 


\section{Keywords}

Water Quality Target Management, Water Quality Improvement Programs, Mike11 Model

\section{Introduction}

With the continuous growth of population and the rapid development of urbanization, as well as the emergence of megacities and urban agglomerations, a large amount of uncontrolled domestic sewage and industrial wastewater has been discharged into urban rivers, and the quality of large-scale regional water environment and the water ecological status continue to deteriorate, posing new challenges to urban water system and water environment management [1] [2] [3]. Urban water system is one of the most important components of sustainable urban development, and it bears important natural and social functions [4] [5]. On the one hand, it maintains the natural water cycle and ecological environment; on the other hand, it undertakes many types of urban needs such as flood control, drainage and landscape construction. Therefore, almost all urban river networks have experienced different levels of canalization, dam and sluice control and other types of manual intervention [6]. This directly changes the river form and connectivity, increases water retention time and water exchange cycle, and leads to the decrease of water environment capacity. Meanwhile, due to the lag in the construction of water environmental protection measures, the urban rivers generally suffer from serious exogenous and endogenous pollution. Thus, the water environment improvement of urban river network has become one of the main focuses worldwide for city managers, planners and the public [7] [8] [9] [10]. The regulation of water environment improvement of urban river network is very complicated. It is needed to adopt comprehensive regulation measures including surface runoff pollution control [11], sewage collection and treatment [12], non-point source pollution control [13] and water supply regulation [6]. In addition, it is necessary to control population growth and implement strict water conservation to reduce and control domestic water pollutants from the source [14].

Currently, water quality target management has been introduced in legislation of many developed countries as the basic policy for water environment management, including the Clean Water Act in the United States [15] and the Nitrates Directive and Water Framework Directive (WFD) in Europe [16]. The US Clean Water Act and Maximum Daily Load Management (TMDL) determine environmental capacity based on water function and control watershed pollution load based on environmental capacity [17]. The WFD is based on the water ecological goal and its associated watershed pollution control, and it seeks to improve or maintain water quality through the establishment of Programmes of Measures and the development of River Basin Management Plans, which can be 
implemented to ensure that each water body within a river basin district achieves good ecological and chemical status [18] [19].

For the water pollution control in China, it has been staying at the total amount control level of setting emission targets for main pollutants, which is not closely connected with water quality targets, and is not enough to support the improvement of water environment quality of river basins. It lacks systematic research on watershed scale and the technical basis of water quality target management is insufficient, which are two important reasons why the deterioration of water quality in China has not been most effectively improved. Although the total capacity control is constraint by the water quality target, the application is limited in the urban watershed with water shortage and high development intensity. In this type of basin, the natural runoff is scarce and the water body has almost no environmental capacity, which results in great difficulties to implement total capacity control. Thus, the total pollutant load control program currently implemented in China will be supplemented by the water quality target-oriented management to form the framework for future medium- and long-term watershed management in China.

Water quality models can be useful tools to simulate and predict chemical pollutants in water environment, and the modeling results from these models under different pollution scenarios can provide a technique support for environmental management agencies to make right decisions. In view of the practice of water environment protection in the European and American developed countries, water environment models have been widely used in the process of documenting and implementing legally effective water pollution prevention and environmental planning as well as total pollutant emission reduction schemes [20] [21] [22] [23]. MIKE11 has been widely and successfully applied to simulate and forecast water quality and assess the water pollution control effect. Therefore, it can be considered to be an effective tool for assisting authorities in managing catchments to achieve statutory water quality targets [24]-[29]. The scientific nature of its numerical simulation has been recognized worldwide [30] [31] [32], and it has also been recommended as one of the water environment regulation models in the current water environmental impact assessment guidelines (Revised Edition) of China [33].

The North Canal River is a typical water shortage urban river in North China, which has both crisis of water resource shortage and water environment pollution. It is urgent to find suitable technological method to improve water quality of this kind of river basin. In this thesis, Beijing part of this seriously polluted river basin is selected as the object area to explore the technical solutions for achieving water quality standards, and the base year is 2013 . This study aims at easing the contradiction between water resource shortage and water environment pollution in the target basin. It can also provide a reference solution for water pollution control of urban river basin in North China and another similar metropolis in the world. 


\section{Materials and Methods}

\subsection{Study Area}

The North Canal River system originates from the south of the Yanshan Mountains. The upstream of the river is Wenyu River. It is called the North Canal River (NCR) from the Beiguan Sluice of Tongzhou district, and it flows out of Beijing near the Yangwa Sluice of Tongzhou. The total length of the mainstream of the river in Beijing is $94 \mathrm{~km}$ and the basin area is $4249 \mathrm{~km}^{2}$. According to the water system pattern of "storage in the west and drainage in the east" in Beijing, the NCR system undertakes the main drainage task of the city. The main tributaries including Qing River, Ba River, Tonghui River and Liangshui River all flow through the central city. The amount of water flowing out of Beijing from the river accounts for $72 \%$ to $90 \%$ of the total according to the statistical data in recent 10 years. The degree of water resource development and utilization is very high in Beijing city which suffers from a serious water shortage. There is almost no natural runoff in the downstream river which takes the sewage treatment plant water and other types of sewage as the main source of water. Thus, there is basically no self-purification capacity in the water bodies of the river. Among the five major water systems of the city, the level of urbanization of NCR basin is the highest and the water quality is the worst, with an average compliance rate of only $17.6 \%$. The water pollution of the river is mainly dominated by both organic pollution and nutrient pollution. The main pollution indicators are ammonia nitrogen $\left(\mathrm{NH}_{3}-\mathrm{N}\right)$, chemical oxygen demand (COD), and total phosphorus (TP), among which the $\mathrm{NH}_{3}-\mathrm{N}$ is the most prominent one. According to the results of surface water environmental assessment in Beijing in 2013, the water quality of the main evaluation reaches of NCR is completely below Grade V standard. The water bodies exceeding the water quality standard are mainly distributed in the Grade IV and V water function zones. The average concentration of $\mathrm{NH}_{3}-\mathrm{N}$ in Grade IV and V water function zones of the river was $6.1 \mathrm{mg} / \mathrm{L}$ and $12.1 \mathrm{mg} / \mathrm{L}$ in 2013 , which was 3.06 and 5.05 times higher than the standard value, respectively. Among the main tributaries, the pollution of Qing River, Ba River, Xiaozhong River and Liangshui River is quite serious, and the concentration of $\mathrm{NH}_{3}-\mathrm{N}$ exceeded the permissible limit of 4.64-11 times. While the pollution in the Tonghui River was relatively light, the $\mathrm{NH}_{3}-\mathrm{N}$ concentration exceeded the limit of 2.05 times. The mean value of COD in Grade IV and V water function zones of the NCR was $41.1 \mathrm{mg} / \mathrm{L}$ and $56.9 \mathrm{mg} / \mathrm{L}$, which was $37 \%$ and $42 \%$ over the permissible limit respectively. Based on the measured data in 2017, it was observed that the average concentration of $\mathrm{NH}_{3}-\mathrm{N}$ of the whole city had reduced by $55.9 \%$ since the implement of Beijing's Action Plan for Prevention and Control of Water Pollution (in abbreviation as the Action Plan) [34]. The improvement effect in the NCR basin is the most significant; however, the water pollution of the basin is still the worst among the five river systems. The overview of the Beijing NCR basin is shown in Figure 1. 


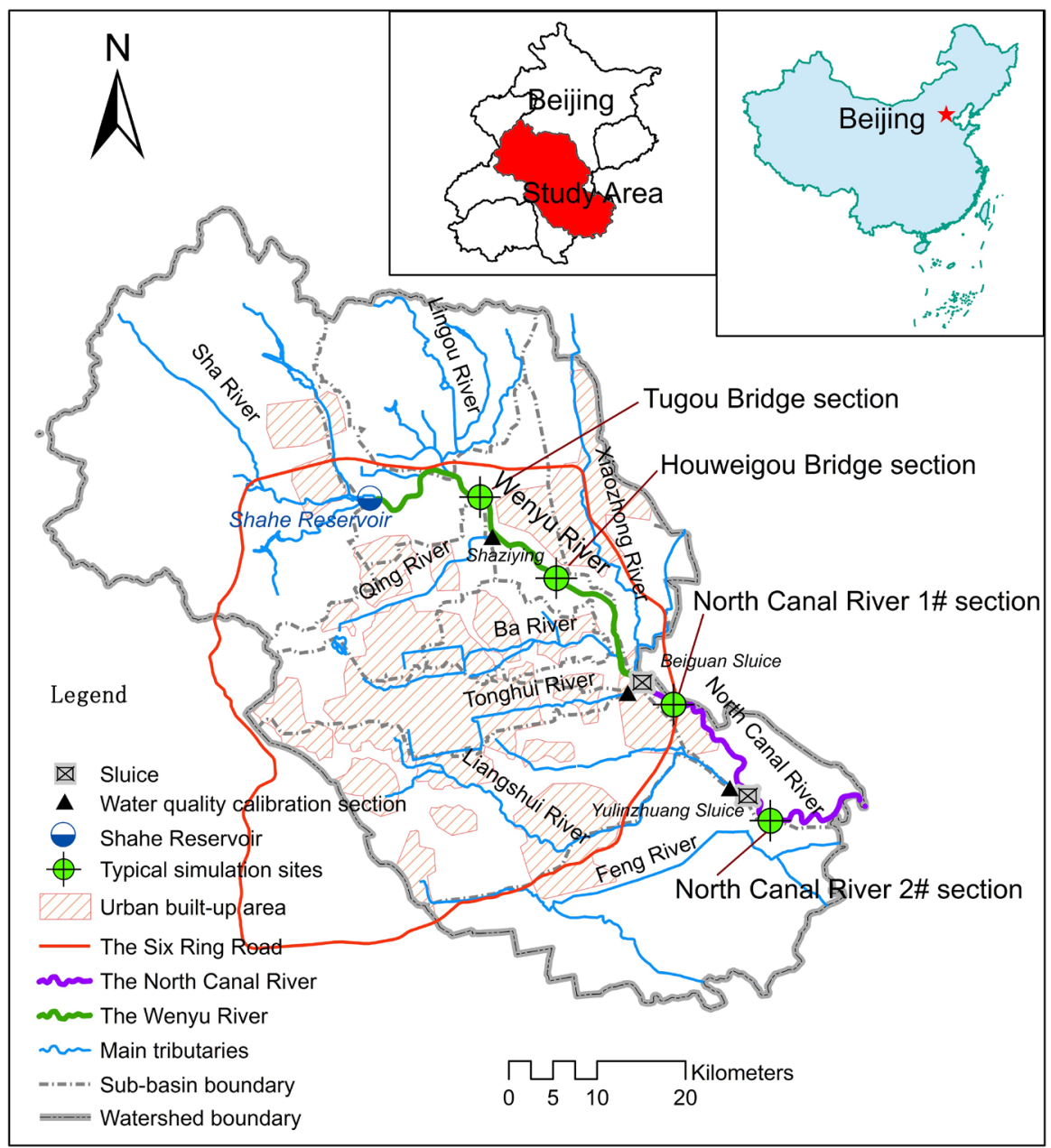

Figure 1. The overview of the Beijing north canal river basin.

\subsection{Data Sources and Processing}

The water pollution control of Beijing is still in the stage of total amount control of pollutants. The $\mathrm{NH}_{3}-\mathrm{N}$ and COD were regarded as the priority-controlled pollutants, and they have always been on the list of mandatory reductions in key pollutants since the "tenth five-year plan" period (10th FYP, 2001-2005) of China for water quality protection. Thus, these two pollutants were selected to characterize the effect of the water quality improvement practice in the NCR basin.

In this paper, the emissions information of water pollution sources includes industrial sources, agricultural sources, life sources and urban runoff pollution, among which the first three are listed in the Beijing's Environmental Statistics Handbook. Industrial sources include key industrial enterprises under supervision and non-key industrial sources. Agricultural sources include pollution from livestock and poultry breeding, planting and aquaculture. Life source pollution includes recycled water treated by centralized disposal facilities (i.e., effluent water of sewage treatment plant and landfill sites) and sewage of urban and rural areas directly discharged into the river. Compared with China's 12th FYP emission reduction accounting scope, this study increases pollution loads in rural life 
emissions and urban runoff, basically covering all the pollution sources. The type and data source of water pollution source in this study are listed in Table 1.

Based on the environmental statistics of Beijing in 2013, the emission amount of various types of pollution sources in the NCR basin was calculated. The data of Beijing's Environmental Statistics Handbook in 2013 was directly used for the emissions of point sources such as industrial sources, livestock and poultry breeding, sewage treatment plant and landfill sites. Each type of point source emission can be easily allocated to corresponding sub-basin of the NCR, according to their spatial coordinates and the receiving water body. The pollutant amount from urban domestic sewage without treatment was obtained by deducting the part of sewage treatment plant from the total production of domestic pollutants. The pollutant excretion coefficient method was adopted to calculate the total production of domestic pollutants. The excretion coefficient of $\mathrm{NH}_{3}-\mathrm{N}$ and COD for the urban population was 9.7 and 79 gram per person per day [35], respectively. For the rural life source, due to a relatively low intact rate and operating ratio of rural sewage treatment facilities, the rural sewage treatment rate and standard are generally very low. Therefore, the rural life sewage is considered as being directly discharged into the river without treatment. The excretion coefficients of $\mathrm{NH}_{3}-\mathrm{N}$ and COD for the rural population were 4 and 16.4 gram per person per day [36], respectively. The population data of each district of Beijing can be downloaded from Beijing Statistics Information Network. The population information was then reassigned to different sub-basins according to the area ratio of each district in the corresponding sub-basin.

The pollution loads in urban runoff were estimated using the modified Johnes's export coefficient method [37]. The formula is as follows:

$$
L=\sum_{i=1}^{n} \sum_{j=1}^{k} C_{i j} \times A_{i} \times H_{j} \times \varphi \times 10^{-3}
$$

where: $L$ represents the output load of urban non-point source pollutants, ton; $C_{i j}$ represents the average mass concentration of a pollutant corresponding to the $i$-type urban underlying surface under the $j$-type of rainfall, $\mathrm{mg} / \mathrm{L} ; A_{i}$ represents

Table 1. Data source and processing of different types of water pollution sources

\begin{tabular}{|c|c|c|}
\hline Pollution source type & Sub-type & Data source \& processing \\
\hline Industrial sources & $\begin{array}{l}\text { Key industrial enterprises and } \\
\text { non-key industrial sources }\end{array}$ & $\begin{array}{l}\text { Beijing's Environmental } \\
\text { Statistics Handbook in } 2013\end{array}$ \\
\hline Agricultural sources & $\begin{array}{l}\text { Planting, livestock and poultry breeding } \\
\text { and aquaculture }\end{array}$ & \\
\hline \multirow[t]{2}{*}{ Life sources } & Sewage treatment plants and landfill sites & \\
\hline & Domestic sewage without treatment & $\begin{array}{l}\text { Beijing Statistics Information } \\
\text { Network; pollutant excretion } \\
\text { coefficient method }\end{array}$ \\
\hline Urban runoff pollution & $\begin{array}{l}\text { Road, square, parking lot, roof, woodland } \\
\text { and grassland }\end{array}$ & $\begin{array}{l}\text { On-site monitoring, Beijing landuse } \\
\text { data in } 2013 \text {; modified Johnes's } \\
\text { export coefficient method }\end{array}$ \\
\hline
\end{tabular}


the area of the $i$-type city underlying surface, $\mathrm{km}^{2} ; H_{j}$ represents the amount of $j$-type of rainfall, $\mathrm{mm} ; \phi$ is an integrated rainfall-runoff coefficient; $10^{-3}$ is an unit conversion factor.

The urban underlying surface is divided into six types of road, square, parking lot, roof, woodland and grassland in this study. According to the classification of rain intensity, there are five types of rainfall including light rain, moderate rain, heavy rain, rainstorms and heavy rainstorms. The average mass concentration data of main pollutants were obtained according to the on-site monitoring results of 13 rainfall processes and 29 typical monitoring sites in Haidian, Dongcheng, Daxing, Shunyi and Fengtai districts of Beijing from 2009 to 2012. The integrated rainfall-runoff coefficient was calculated by weighted average calculation of different runoff surface coefficients given by the relevant design standard.

In addition to pollution source data, a lot of hydrological, environmental, and topographic data were used for the MIKE11 model building, parameter calibration and verification. Among them, the river flow data (including dam discharge flow), daily water level data in the upper and lower reaches near dams, as well as rainfall station and evaporation station data for the rainfall-runoff module were provided by Beijing Hydrological Station. The monthly water quality data of main monitoring sections were provided by Beijing Environmental Protection Monitoring Center. The river sewage outlet information including both flow and main pollutants concentration was obtained from Beijing Pollution Source Survey Information Database. The topographic data of 16 river sections were obtained by field measurement. Planning information for simulation scenario settings mainly came from the Action Plan as well as other related planning documents. The discharge standards of water pollutants were controlled according to two local standards (DB 11/890-2012, DB 11/307-2013) for water pollution prevention of Beijing. The data sources for model building and simulation scenario settings are listed in Table 2.

\subsection{Pollution Sources Characteristics}

Based on statistical and computational analysis, the total emissions of $\mathrm{NH}_{3}-\mathrm{N}$

Table 2. Data sources of other items for model building and simulation scenario settings.

\begin{tabular}{|c|c|c|}
\hline Item & Data type & Data source \\
\hline \multirow{5}{*}{$\begin{array}{l}\text { Data for model building, parameter } \\
\text { calibration and verification }\end{array}$} & Flow and water level data & Beijing Hydrological Station \\
\hline & Rainfall and evaporation data & \\
\hline & Water quality data & Beijing Environmental Protection Monitoring Center \\
\hline & River sewage outlet information & Beijing Pollution Source Survey Information Database \\
\hline & Topographic data & Field measurement \\
\hline \multirow[t]{2}{*}{$\begin{array}{l}\text { Planning information for } \\
\text { simulation scenario settings }\end{array}$} & $\begin{array}{l}\text { Basic emission reduction measures, intensive } \\
\text { measures for water quality improvement }\end{array}$ & The Action Plan; other related planning documents \\
\hline & Discharge standard of water pollutants & $\begin{array}{l}\text { Discharge standard of water pollutants for municipal } \\
\text { wastewater treatment plants (DB 11/890-2012); Integrated } \\
\text { discharge standard of water pollutants (DB 11/307-2013) }\end{array}$ \\
\hline
\end{tabular}


and COD in the NCR basin in 2013 were 12.1 and 123.7 thousand tons, respectively. The composition of $\mathrm{NH}_{3}-\mathrm{N}$ and COD pollution was presented in Figure 2. The largest emission is the life source followed by the agricultural source, the urban runoff source and the industrial source emission.

\subsection{Water Quality Targets}

Based on the "Environmental Quality Standards for Surface Water" of China (GB 3838-2002), the surface water environment is divided into five grades, and each grade has its corresponding standard value. The upper reach of Wenyu River (U-WR, from the Shahe Reservoir dam site to the section near Shaziying sluice) belongs to Grade IV water bodies. While the lower Wenyu River (L-WR, from the section near Shaziying sluice to Beiguan sluice section) and the NCR belong to Grade $\mathrm{V}$ water bodies. The standard value of $\mathrm{NH}_{3}-\mathrm{N}$ and COD for Grade IV water bodies is $1.5 \mathrm{mg} / \mathrm{L}$ and $30 \mathrm{mg} / \mathrm{L}$, respectively, and that for Grade $\mathrm{V}$ is $2 \mathrm{mg} / \mathrm{L}$ and $40 \mathrm{mg} / \mathrm{L}$, respectively. According to the water quality data observed in 2013, the average concentration of main water pollutants, especially the $\mathrm{NH}_{3}-\mathrm{N}$, is far beyond the standard value (see in Table 3 ).

\subsection{Basis for Scenario Settings}

\subsubsection{Prediction of Population Change}

The emission of life source accounts for the largest proportion of all kinds of pollution sources, thus the reasonable prediction of future population change is a key to accurately predict the emission of the major pollutants. The outline of the coordinated development plan for the Beijing-Tianjin-Hebei region proposes that the total resident population must be controlled within 23 million in Beijing by 2020 and the population of central city will decrease by $15 \%$. Because $86 \%$ of

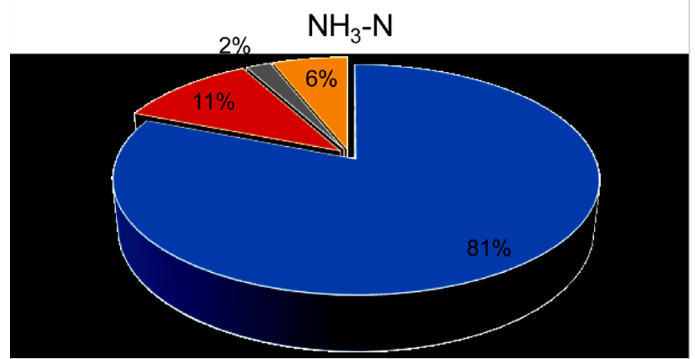

- life " agriculture " industry "urban runoff

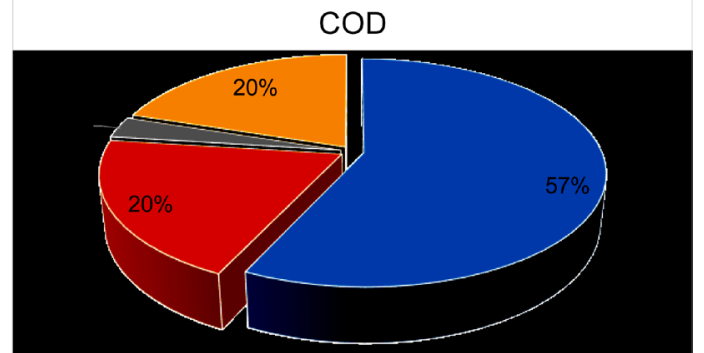

- life " agriculture " industry "urban runoff

Figure 2. The composition of $\mathrm{NH}_{3}-\mathrm{N}$ and COD pollution.

Table 3. Comparison of water quality targets and observed values in 2013.

\begin{tabular}{|c|c|c|c|c|c|}
\hline \multirow{2}{*}{ River } & \multirow{2}{*}{ Water functional zones } & \multicolumn{2}{|c|}{$\mathrm{NH}_{3}-\mathrm{N}(\mathrm{mg} / \mathrm{L})$} & \multicolumn{2}{|c|}{$\mathrm{COD}(\mathrm{mg} / \mathrm{L})$} \\
\hline & & Standard value & Observed value in 2013 & Standard value & Observed value in 2013 \\
\hline L-WR & $\mathrm{V}$ & $<2$ & $14.75(9.24 \sim 21.6)$ & $<40$ & 49.5 \\
\hline NCR & $\mathrm{V}$ & $<2$ & $16.22(8.9 \sim 23.5)$ & $<40$ & 49.4 \\
\hline
\end{tabular}


the central city area is distributed in the NCR basin, a total of approximately 1.65 million permanent residents will be reduced in this basin. At the same time, the population will increase in the suburban districts which undertake the function of accepting the population of the central city. In addition, considering the setup of Tongzhou district as the subsidiary administrative center of Beijing, population migration as well as population aggregation caused by regional economic development will also increase the population of Tongzhou district.

Relative to the urban population, the rural population generally distributed in the suburbs of the county, will be less affected by the population control policy. According to the population number in 2013 and the total 23 million population control red line in 2020 , the average annual population growth rate cannot exceed $1.2 \%$ during the "13th five-year plan" period (13th FYP, 2016-2020) of China and the rural population incremental scale of the NCR basin is about 100 thousand. At the same time, due to the impact of transformation construction of the urban and rural adjacent areas, urban villages and shantytowns, as well as the implementation of the national new urbanization construction, the number of rural populations may also show no significant change or even decreases.

\subsubsection{Control Measures and Levels for Major Pollution Sources}

1) Sewage Treatment Plants

The scenario of the capacity and level of sewage treatment was set based on the goals and requirements proposed in the Action Plan, which had been issued by the Beijing municipal government in December 2015. A definite goal on the municipal sewage treatment capacity of Beijing at the end of the 13th FYP of China has been put forward in this plan. In this study, the sewage treatment capacity goals in the basic scenario scheme are consistent with those of the Action Plan. The discharge limits of municipal sewage treatment plants regulated by the DB 11/890-2012, the concentrations of COD and $\mathrm{NH}_{3}-\mathrm{N}$ of the effluent water of municipal sewage treatment plants were set $30 \mathrm{mg} / \mathrm{L}$ and $1.5 \mathrm{mg} / \mathrm{L}$, respectively. Rural sewage treatment facilities are relatively simple, and their effluents were set according to the discharge standard regulated in the DB 11/307-2013.

2) Industrial Sources

Because of the continuous adjustment and optimization of urban function orientation, the emission of industrial sources in Beijing accounts for a small proportion in recent years. The possibility for further emission reduction in industrial source is very small. Thus, the industrial source emissions forecast can be appropriately simplified. According to the Action Plan, the key industrial enterprises should strictly execute the discharge standard of DB 11/307-2013. As an important measure for source control of pollutants, the enterprises which do not meet the municipal industrial policies and seriously contaminate the river, should be eliminated gradually. In addition, the industrial space layout should be further optimized, and industrial enterprises are encouraged to be assembled to industrial parks. 
3) Agricultural Sources

Considering that the livestock and poultry pollution accounts for the largest proportion of the total agricultural source pollution, its governance should be the focus of agricultural pollution control. According to related agricultural management planning, it will not be allowed to establish new and enlarge the existing large-scale livestock and poultry farms after 2020. The layout of livestock and poultry breeding should be further adjusted and optimized according to the land carrying capacity and the evaluation of spatial suitability of existing farms. Prohibited breeding area will be designated and all the farms in this district will be closed.

4) Urban Runoff Pollution

It is encouraged to promote the early stormwater collection and utilization under the technology guide for sponge city construction-low impact development stormwater system construction (trial) issued by MOHURD [38]. Runoff control targets for major cities in different zones of China are proposed in this guide. Considering the differences in natural conditions such as climate characteristics and soil geology, as well as economic conditions, the Chinese mainland is divided into five sub-areas. Beijing is located in Zone III, the recommended value of the volume capture ratio of annual runoff is $75 \%-85 \%$. The suspended solids (SS), COD, TN, TP and other types of pollutants together with the runoff into the river would be synchronously reduced. Considering the randomness and complexity of runoff pollutants change, the control rate of runoff pollution can be simply set to a value lower than the runoff control rate. In addition, a part of the total runoff controlled is the detention volume which will be discharged after the flood peak, and the rest is stormwater retention available for use. Because the change of water volume can affect the contaminant migration, the rate of stormwater resources utilization should be considered in different simulation schemes.

\subsubsection{Protection Policy of Ecological Base Flow}

Specific measures in terms of water ecological environment protection and assurance of ecological base flow have been put forward in the Action Plan. It is required in this plan to carry out ecological water demand analysis of the river and lake, in order to determine the ecological base flow, and to increase the amount of ecological water use in river and lake. For the watershed management of the NCR basin, it is recommended to take measures of ecological replenishment, collection and purification of the initial stormwater and other measures to ensure water quality stability of the upper reach of Qing River, and improve water quality of the upper reach of Liangshui River, the lower reach of Tonghui and Ba River, and also eliminate the water bodies Grade V below in the lower reach of Qing River and other river reaches.

At present, the first phase of the Middle Route of South-to-North Water Transfer Project of China has been put into service. It is able to supply 1.05 billion $\mathrm{m}^{3}$ water for Beijing every year. The water amount of the second phase of 
the project will increase to 1.49 billion $\mathrm{m}^{3}$, which will be realized in $2030 \mathrm{ac}$ cording to the national planning. According to the approved planning of the overall configuration of the diversion water in Beijing city, the water allocated to the river and lake is approximately 0.09 billion $\mathrm{m}^{3}$ during the first phase of the project; and that will reach 0.145 billion $\mathrm{m}^{3}$ during the second phase.

\subsection{Principles and Methods of Model MIKE11}

In this paper, both the Hydrodynamics Module (HD Module) and the Advection-diffusion Module (AD Module) of MIKE11 were used to establish the water dynamics and quality model of the Beijing NCR basin. The upstream flow and the downstream water level were taken as the external boundary conditions in this model. At the same time, the internal boundary conditions were set considering the effect of the control and regulation of ten sluices as well as the inflow of twelve trenches or tributaries, and that of 53 pollution sources directly into the mainstream of the river and 28 pollution sources into the Qing River, Tonghui River, Liangshui River and the other major tributaries. In addition to the point sources, the urban runoff pollution and agricultural non-point source pollution were also considered in this model. And these two types of pollution were considered as the form of line source into the river with the rainfall-runoff. Limited by the size of the paper, the basic principles and the detailed modeling process of the MIKE11 model were not presented in this work. Here we only briefly introduce the model calibration and verification effects. The detailed information of the model can be referenced from the authors' another literature [39].

\subsection{Design Flow Conditions}

As there is almost no natural runoff in the target river basin, the major water sources are the urban sewage treatment plant water and other types of sewage. Thus, the flow conditions which affect the hydrodynamic and water quality simulation of the river are actually the different scenarios of drainage conditions, rather than the natural runoff of the different guarantee rates. According to the outbound water quantity change of the river from 2003 to 2014, the main factor influencing the outbound water volume was the change of the precipitation in the basin. Therefore, the river flow data of 2010 (the equivalent of 90\% precipitation frequency) which is relatively complete and easily obtained, was taken as the design flow for the model building and water quality simulation of different scenarios in this study.

\section{Results and Discussion}

\subsection{Model Performance}

The Yulinzhuang section in the downstream of the NCR was taken as the typical section for hydrodynamic parameter calibration. This section has long series of water level data and flow data, and is also a national section of China for Bei- 
jing's outbound water quality assessment. The Yulinzhuang section as well as some typical sections in tributaries, including Shaziying in Qing River, Tonghui Bridge in Tonghui River, Xugezhuang in Liangshui River, were selected for the water quality calibration and verification.

The water level simulated by the model is basically consistent with the measured value of the Yulinzhuang section (see in Figure 3). The water quality simulation effect of some typical sections was shown in Figure 4. The error of simulated concentration of $\mathrm{NH}_{3}-\mathrm{N}$ and $\mathrm{COD}$ in the water quality calibration and

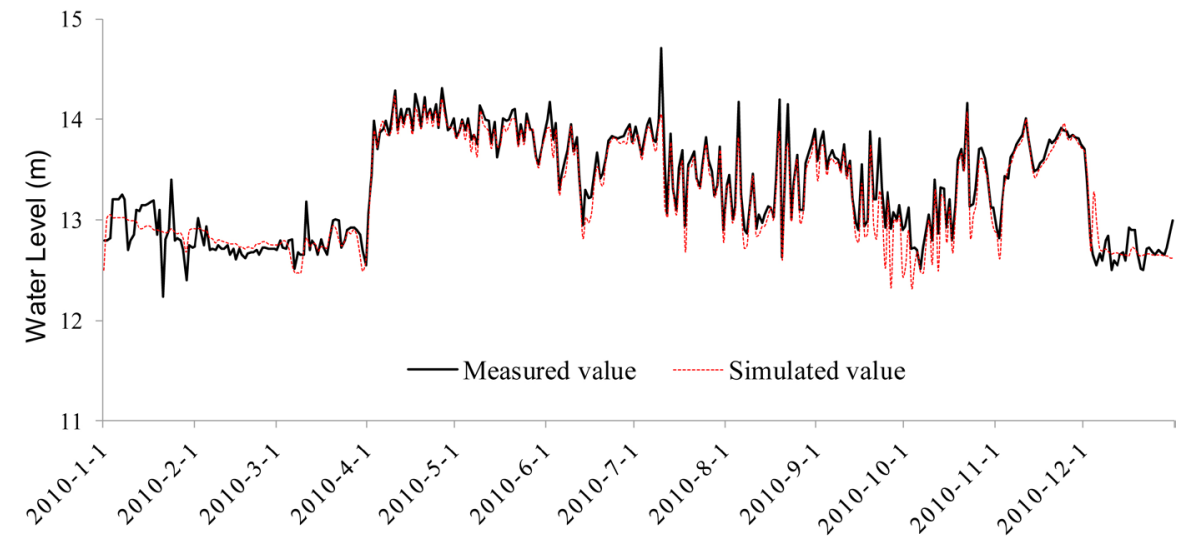

Figure 3. The comparison of the simulated and observed water levels of Yunlinzhuang section.
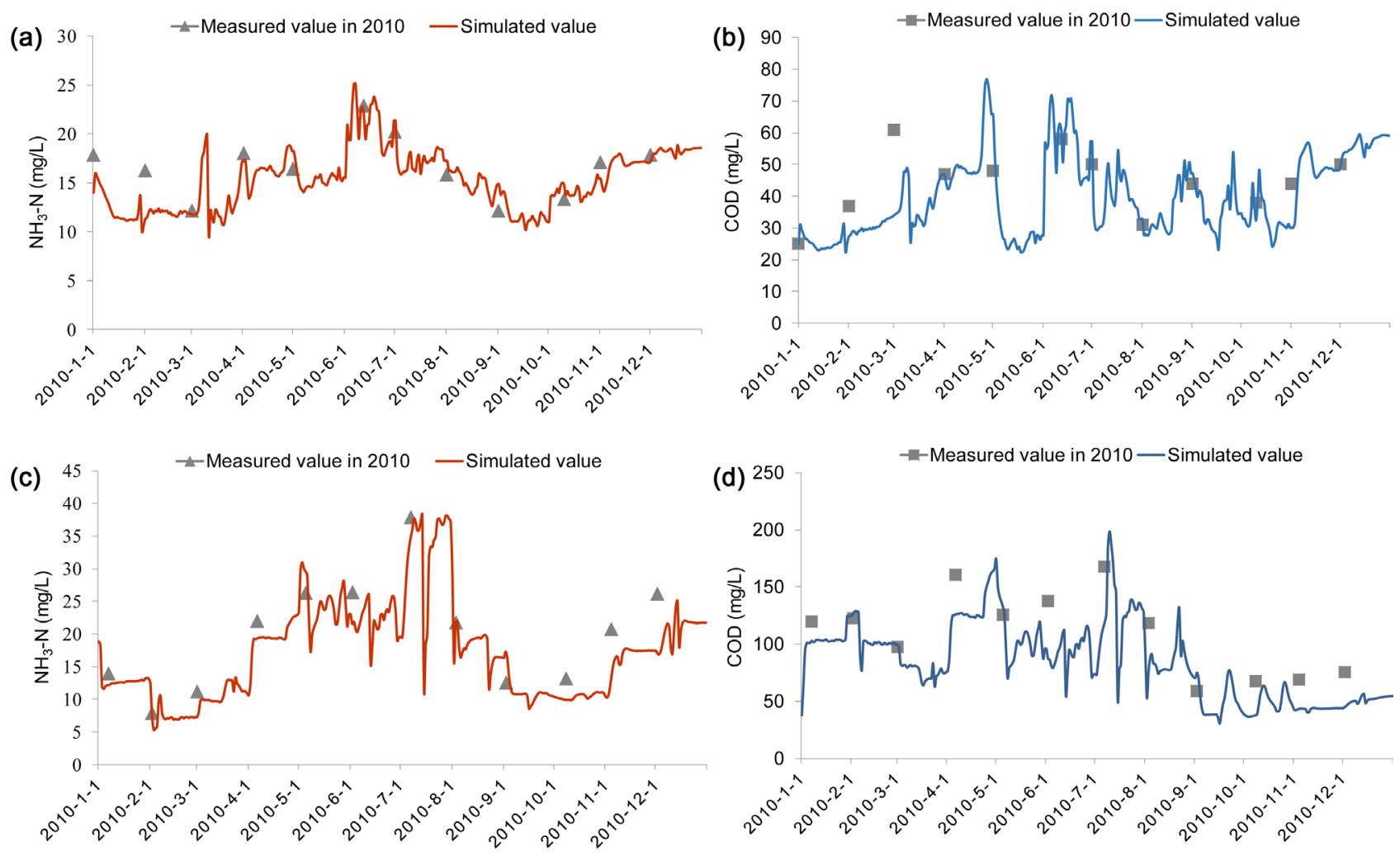

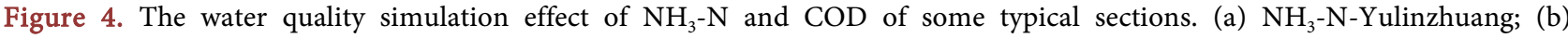
COD-Yulinzhuang; (c) $\mathrm{NH}_{3}-\mathrm{N}$-Shaziying; (d) COD-Shaziying. 
verification sections was controlled within a reasonable range. Thus, the related simulation analysis of multiple scenarios can be carried out based on the model.

\subsection{Population Projections}

According to the uncertainties in future population changes, different intensities of population regulation scenarios were set up in the prediction of population changes. The results are shown in Table 4. The medium population regulation program was mainly adopted for water quality simulation. In this program, the resident population of the NCR basin will decrease by 1.24 million, with a proportion of $8 \%$ smaller relative to that of the base year, and the rural population remains unchanged. Under the impact of population regulation policy, the areas where the resident population, especially the urban population is reduced, are mainly distributed in the central urban district of the sub-basins of Ba River, Tonghui River, Qing River and Liangshui River. While, the urban population will significantly increase for the other sub-basins including the NCR, Feng River, Xiaozhong River and Sha River, which are involved in the subsidiary administrative center construction or undertake the function of accepting the population of the central city.

\subsection{Simulation Scenarios}

\subsubsection{Basic Emission Reduction Scenarios}

The basic scenario program was set mainly based on the requirements and objectives of the Action Plan. 1) All the sewage discharge enterprises should establish sewage treatment facilities to prevent the straight discharge of sewage, and the discharge standard should meet the requirements of DB 11/307-2013. 2) The area within the Sixth Ring Road is set up as the forbidden area of livestock and

Table 4. Results of population projections of the ten sub-basins of NCR according to different intensities of population regulation scenarios. Unit, 10,000 people.

\begin{tabular}{|c|c|c|c|c|c|c|c|c|}
\hline \multirow{2}{*}{ Sub-basins } & \multirow{2}{*}{$\begin{array}{l}\text { Resident population } \\
\text { in } 2013\end{array}$} & \multicolumn{2}{|c|}{ Week regulation program } & \multicolumn{3}{|c|}{ Medium regulation program } & \multicolumn{2}{|c|}{ Strong regulation program } \\
\hline & & Population & Change & Urban & Rural & Change & Population & Change \\
\hline Ba River & 142.6 & 121.2 & $-15 \%$ & 116.6 & 0.3 & $-18 \%$ & 114 & $-20 \%$ \\
\hline NCR & 19.3 & 26 & $35 \%$ & 16.2 & 8.8 & $30 \%$ & 23.1 & $20 \%$ \\
\hline Feng River & 79.0 & 94.9 & $20 \%$ & 59.2 & 34.1 & $18 \%$ & 90.9 & $15 \%$ \\
\hline Liangshui River & 319.1 & 280.9 & $-12 \%$ & 255.3 & 16.0 & $-15 \%$ & 261.7 & $-18 \%$ \\
\hline Lingou River & 13.9 & 16.4 & $18 \%$ & 5.3 & 10.7 & $15 \%$ & 15.4 & $10 \%$ \\
\hline Qing River & 264.1 & 227.2 & $-14 \%$ & 213.6 & 3.0 & $-18 \%$ & 211.2 & $-20 \%$ \\
\hline Sha River & 134.5 & 158.6 & $18 \%$ & 130.0 & 24.7 & $15 \%$ & 147.9 & $10 \%$ \\
\hline Tonghui River & 382.0 & 324.7 & $-15 \%$ & 312.0 & 0.7 & $-18 \%$ & 305.6 & $-20 \%$ \\
\hline Wenyu River & 73.3 & 86.6 & $18 \%$ & 74.2 & 10.2 & $15 \%$ & 80.7 & $10 \%$ \\
\hline Xiaozhong River & 72.3 & 86.7 & $20 \%$ & 71.3 & 14.0 & $18 \%$ & 83.2 & $15 \%$ \\
\hline Total & 1500.1 & 1423.1 & $-5 \%$ & 1253.5 & 122.4 & $-8 \%$ & 1333.7 & $-11 \%$ \\
\hline
\end{tabular}


poultry breeding, and all the farms in this area should be closed. The fecal control of large-scale pig and cattle farms should be completed, and the resource utilization would be achieved. The agriculture in central urban area (including the whole basin of Ba River, Qing River and Tonghui River, and about half of the Liangshui River Basin) should not be reserved. 3) According to 13th five-year water development plan of Beijing, the per capita living water consumption should not grow under a resource management scheme known as the Most Stringent Water Resources Management System. The full coverage of sewage treatment facilities should be basically realized in the city's built-up area and towns, where sewage will be entirely collected and the urban sewage treatment rate will reach $100 \%$. The rural sewage treatment rate should reach $90 \%$, and the effluent water should meet the relatively strict water quality standard of DB 11/307-2013, with a concentration limit of $5 \mathrm{mg} / \mathrm{L}$ for $\mathrm{NH}_{3}-\mathrm{N}$ and $40 \mathrm{mg} / \mathrm{L}$ for COD. 4) The volume capture ratio of annual runoff should reach $85 \%$, and the control rate of runoff pollution was set up as $80 \%$. Meanwhile, the utilization ratio of storm water was set to $60 \%$.

Under the medium population regulation program, when the basic emission reduction scenarios are applied, the emission amount of $\mathrm{NH}_{3}-\mathrm{N}$ and COD in the NCR basin will be reduced by $83 \%$ and $69 \%$, respectively based on 2013 . The evaluation results are listed in Table 5.

\subsubsection{Intensive Measure Programs}

If the conventional emission reduction measures cannot achieve satisfying results of pollution control, water quality goals should be achieved by strengthening water saving, improving hydrodynamic conditions, increasing water environmental capacity and implementing other comprehensive and strengthening measures.

1) Strengthening Water-Saving

The control of total domestic water consumption would greatly contribute to the reduction of water pollutant emission. According to the National Water Resources Comprehensive Plan (2010-2030) approved by the State Council of China, the national average quota for domestic water use of urban residents in 2030 is forecasted to be 156 liters per person and per day, and that of Beijing city is 143. Then if the drainage coefficient is set to be 0.9 , the daily domestic sewage discharge coefficient is approximately 128 liters per capita. In this study, that value of 202 was initially adopted according to the environmental statistics of Beijing in 2013, and the rural sewage discharge coefficient was estimated to be

Table 5. Forecast results of basic emission reduction scenarios. Unit, tons.

\begin{tabular}{cccc}
\hline \multirow{2}{*}{ Item } & \multicolumn{3}{c}{ Medium population regulation program } \\
\cline { 2 - 4 } & Emission amount & Reduction amount & Reduction ratio \\
\hline $\mathrm{NH}_{3}-\mathrm{N}$ & 2073 & 10,011 & $-83 \%$ \\
$\mathrm{COD}$ & 38,384 & 85,306 & $-69 \%$ \\
\hline
\end{tabular}


133 based on relevant literature review. In accordance with the above national plan, the urban domestic water saving potential of Beijing can reach a maximum of $36 \%$. Therefore, three intensities of domestic water-saving schemes of low (urban and rural domestic water quota are reduced by $10 \%$ and $5 \%$, respectively), medium (urban domestic water quota is reduced by $25 \%$, and rural ones $15 \%$ ) and high (urban domestic water quota is reduced by $36 \%$, and rural ones $25 \%$ ) have been set in this study.

The effects of emission reduction for different water-saving schemes are shown in Table 6. Under the medium population regulation program, if the medium water-saving scheme is adopted, a reduction of 386 tons for life source $\mathrm{NH}_{3}-\mathrm{N}$ emission can be realized, and COD emission will decrease by 7216 tons, with a reduction ratio of $19 \%$. Thus, from the point of view of source control, better emission reduction effect can be achieved by water saving and pollution reduction, other than the end-point treatment.

\section{2) Ecological Base Flow Protection}

The ecological base flow of the U-WR is mainly derived from Shahe Reservoir release. This reservoir is a water supply reservoir for agricultural irrigation. In recent years, the reservoir release happens only under the flood control situation. Taking the $90 \%$ precipitation frequency year of 2010 as an example, there are totally 184 days without reservoir release. Based on the historical reservoir release in dry season (during December, January and February), a discharge flow of $1.2 \mathrm{~m}^{3} / \mathrm{s}$ was set for environmental flow need in the lower reaches. As the reservoir has the main function of agricultural water supply with Grade IV functional water bodies, the release water quality is also set according to the same grade standard value.

3) Drainage Communication

In accordance with the requirements of speeding up the construction of drainage communication and regional water circulation projects in Beijing city, the "three-ring water systems" and the regional drainage communication pattern will be gradually established. The degradation rate of water pollutants can be accelerated to a certain extent when the fluidity of river and lake water bodies is enhanced, and the self-purification and pollution capacity of water bodies can be then improved. In this study, we set up three scenarios with an increase of $50 \%$, $100 \%$ and $200 \%$ in the comprehensive degradation coefficient of the main pollutants, relative to the baseline scenario. These three scenarios correspond to the

Table 6. Forecast results of emission reduction based on strengthening water-saving schemes. Unit, tons.

\begin{tabular}{ccccccc}
\hline \multirow{2}{*}{ Item } & \multicolumn{2}{c}{ Low scheme } & \multicolumn{2}{c}{ Medium scheme } & \multicolumn{2}{c}{ High scheme } \\
\cline { 2 - 7 } & $\begin{array}{c}\text { Reduction } \\
\text { amount }\end{array}$ & $\begin{array}{c}\text { Reduction } \\
\text { ratio }\end{array}$ & $\begin{array}{c}\text { Reduction } \\
\text { amount }\end{array}$ & $\begin{array}{c}\text { Reduction } \\
\text { ratio }\end{array}$ & $\begin{array}{c}\text { Reduction } \\
\text { amount }\end{array}$ & $\begin{array}{c}\text { Reduction } \\
\text { ratio }\end{array}$ \\
\hline $\mathrm{NH}_{3}-\mathrm{N}$ & 152 & $-7 \%$ & 386 & $-19 \%$ & 564 & $-27 \%$ \\
$\mathrm{COD}$ & 2867 & & 7216 & & 10456 & \\
\hline
\end{tabular}


low, medium and high intensities of drainage communication schemes, respectively in the simulation.

4) Ecological Water Replenishing

It is proposed in the Action Plan that ecological water replenishment should be prioritized in the Qing River. The Qing River is an important tributary of the Wenyu River currently with severe black and odorous water bodies. It is estimated that the implementation of various types of comprehensive emission reduction measures is still not enough to eliminate the water bodies inferior Grade V function in the Qing River throughout the year. Bearing in mind that the main purpose of ecological water replenishment here is to eliminate the black and odorous water bodies in the Qing River, thus the magnitude and period of water replenishment is not fixed. For example, when not considering the water-saving schemes, the water replenishment should be executed during the period of January-April, June-July and December, with a total of 41.75 million $\mathrm{m}^{3}$. While if the medium domestic water-saving scheme is further adopted, the water replenishment should only be executed in January, February, April and December, with a total of 16.25 million $\mathrm{m}^{3}$. And if the high water-saving scheme is further adopted, the amount of water replenishment will decrease to 7.7 million $\mathrm{m}^{3}$ which is less than one fifth of that without considering water saving schemes.

5) Reinforcement Scheme in Key Basins

Both the Tonghui River and Liangshui River are the focus and difficulties of water environment management in the NCR basin. According to the results of model calculation, even under the high water-saving scheme in 2030, the annual average concentrations of $\mathrm{NH}_{3}-\mathrm{N}$ of the Tonghui bridge section in Tonghui River and Xugezhuang section in Liangshui River were $2.61 \mathrm{mg} / \mathrm{L}$ and $3.64 \mathrm{mg} / \mathrm{L}$, respectively, which could still fail to meet the water quality targets of Grade $\mathrm{V}$ standard water bodies. After the two tributaries converge into the NCR, the water quality of the mainstream in the lower reach will be adversely affected. According to the discharge structure of $\mathrm{NH}_{3}-\mathrm{N}$, the sewage treatment plant emission accounts for the largest proportion. However, the effluent water of sewage treatment plant has already met the discharge standard of Grade IV water bodies, and the space for further emission reduction is extremely small. In addition to the sewage treatment plant emission, the urban non-point source is the biggest one of Tonghui River Basin. It ranks first of the 10 sub-basins of NCR, accounting for more than $30 \%$ of total emission. While for the Liangshui River Basin, the industrial source emission accounts for a large proportion, and it is also the largest in the 10 sub-basins, accounting for $42 \%$ of the total emission. Therefore, the water pollution control of the Tonghui River and Liangshui River can be proceeded from urban non-point source and industrial source, respectively, in order to further tap the potential of emission reduction.

The Action Plan proposed a solution for urban runoff pollution in the Tonghui River Basin which will be taken as a pilot of early rainwater collection and treatment. According to the simulation results, if 45 tons of the urban non-point 
source pollutants in the Tonghui River Basin are effectively controlled, the average annual concentration of $\mathrm{NH}_{3}-\mathrm{N}$ in Tonghui Bridge section can be reduced from $2.61 \mathrm{mg} / \mathrm{L}$ to $2.18 \mathrm{mg} / \mathrm{L}$. It is also proposed in the Action Plan that the industrial layout should be optimized, and industrial enterprises are encouraged to move to industrial parks. It is estimated that the optimization of the industrial spatial layout can reduce a total of 34 tons of industrial source pollutants in the Liangshui River Basin, and the annual average concentration of $\mathrm{NH}_{3}-\mathrm{N}$ in $\mathrm{Xu}$ gezhuang will decrease from $3.64 \mathrm{mg} / \mathrm{L}$ to $3.23 \mathrm{mg} / \mathrm{L}$.

6) Combined Enhancement Schemes

When an individual measure cannot achieve satisfactory results, combined schemes should be adopted to achieve the water quality goal. There are two categories and 6 items in the combination schemes as follows: one category is the three combination programs based on the medium domestic water-saving scheme. And the other is the three combination programs based on the high water-saving scheme.

i) Combination programs of the medium water-saving scheme, medium drainage communication scheme and ecological water replenishment scheme.

ii) Combination programs of the medium water-saving scheme, medium drainage communication scheme and key basin reinforcement scheme.

iii) Combination programs of the medium water-saving scheme, medium drainage communication scheme, key basin reinforcement scheme, and ecological water replenishment scheme.

iv) Combination programs of the high water-saving scheme and medium drainage communication scheme.

v) Combination programs of the high water-saving scheme, medium drainage communication scheme, and key basin reinforcement scheme.

vi) Combination programs of the high water-saving scheme, medium drainage communication scheme, key basin reinforcement scheme, and ecological water replenishment scheme.

\subsection{Water Quality Simulation and Forecast}

\subsubsection{Selection of Typical Simulation Sites}

It can be reflected by the simulated concentration of the characteristic contaminants of typical simulation sites that whether the simulated river reaches have achieved a relevant standard. Because the U-WR and L-WR belong to different water function zones with different standard values, different simulation sites should be selected for that two simulated river reaches. Though the water function of the L-WR is the same as that of the NCR, the determination of simulation sites should consider the influx of tributaries which may evidently affect the simulation results. Finally, four simulation sites were determined. The Tugou bridge section and the Houweigou bridge are located in the U-WR and L-WR, respectively. The NCR $1 \#$ section is located in the river reach where is after the Tonghui River flows in and before the Liangshui River flows in, and the NCR 2\# section is located in the river reach where is after the Liangshui River converges 
into the mainstream of the NCR. The locations of the four typical simulation sections are shown in Figure 1.

\subsubsection{Results of Water Quality Simulation}

Firstly, the water quality improvement effect of the basic emission reduction scenarios was simulated. In general, the water quality targets of COD can be relatively easy to achieve. Results show that all the simulated COD concentrations of the four indication sections can meet the requirement standards even under the week population regulation program, and the water quality remains stable throughout the year (see in Figure 5(b)). However, the water quality improvement effect for $\mathrm{NH}_{3}-\mathrm{N}$ cannot be satisfied. Even under the strong population regulation program, the simulated $\mathrm{NH}_{3}-\mathrm{N}$ concentration still seriously exceeds the water quality standards (see in Table 7 and Figure 5(a)). Among the four indication sections, only the simulated concentration of the Tugou bridge section can meet the target value (with daily average concentration below 1.5 $\mathrm{mg} / \mathrm{L}$ ), while that of the other sections all exceed the target value of $2 \mathrm{mg} / \mathrm{L}$. The number of days with daily concentration meeting the water quality targets is only 97 and 11 for the NCR 1\#, 2\# sections, respectively. Besides, the peak concentration is very high, especially for the NCR $2 \#$ section.

Thus, intensive measure programs should be implemented to meet satisfactory targets for water quality improvement. On the basis of the medium population regulation program, the effect of reducing the $\mathrm{NH}_{3}-\mathrm{N}$ concentration for
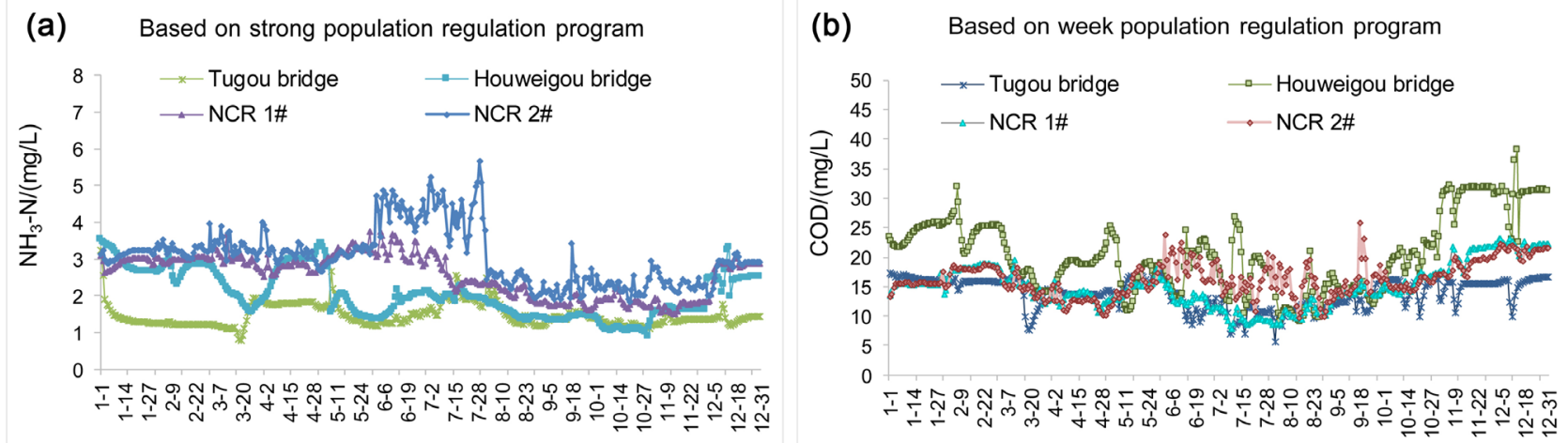

Figure 5. The simulated results of $\mathrm{NH}_{3}-\mathrm{N}$ and COD based on basic emission reduction scenarios. (a) $\mathrm{NH}_{3}-\mathrm{N}$-strong population regulation program; (b) COD-week population regulation program.

Table 7. The simulation results of $\mathrm{NH}_{3}-\mathrm{N}$ based on the strong intensity of population regulation program.

\begin{tabular}{cccc}
\hline Typical simulation sites & $\begin{array}{c}\text { Daily average } \\
\text { concentration, mg/L }\end{array}$ & Qualified days, d & $\begin{array}{c}\text { Peak concentration, } \\
\mathrm{mg} / \mathrm{L}\end{array}$ \\
\hline Tugou bridge & 1.46 & 249 & 2.65 \\
Houweigou bridge & 2.04 & 200 & 3.44 \\
NCR 1\# & 2.58 & 97 & 3.75 \\
NCR 2\# & 3.07 & 11 & 5.65 \\
\hline
\end{tabular}


Table 8. The simulation results of $\mathrm{NH}_{3}-\mathrm{N}$ according to each single intensive measure program. Unit, mg/L.

\begin{tabular}{|c|c|c|c|c|c|c|c|c|c|}
\hline \multirow{2}{*}{$\begin{array}{c}\text { Typical simulation } \\
\text { sites }\end{array}$} & \multirow{2}{*}{$\begin{array}{l}\text { Medium population } \\
\text { regulation program } \\
\text { (base) }\end{array}$} & \multicolumn{3}{|c|}{$\begin{array}{l}\text { Strengthening water-saving } \\
\text { scheme }\end{array}$} & \multirow{2}{*}{$\begin{array}{l}\text { Ecological base } \\
\text { flow protection } \\
\text { scheme }\end{array}$} & \multicolumn{3}{|c|}{ Drainage communication scheme } & \multirow{2}{*}{$\begin{array}{l}\text { Ecological water } \\
\text { replenishing } \\
\text { scheme }\end{array}$} \\
\hline & & low & medium & high & & $\begin{array}{l}\mathrm{k} \text { increases } \\
\text { by } 50 \%\end{array}$ & $\begin{array}{c}\mathrm{k} \text { increases } \\
\text { by } 100 \%\end{array}$ & $\begin{array}{l}\mathrm{k} \text { increases } \\
\text { by } 200 \%\end{array}$ & \\
\hline Tugou bridge & 1.52 & 1.40 & 1.23 & 1.10 & 1.58 & 1.49 & 1.46 & 1.41 & 1.52 \\
\hline Houweigou bridge & 2.10 & 1.92 & 1.66 & 1.46 & 2.04 & 2.07 & 2.04 & 1.99 & 1.75 \\
\hline NCR $1 \#$ & 2.64 & 2.44 & 2.14 & 1.92 & 2.60 & 2.56 & 2.49 & 2.37 & 2.46 \\
\hline NCR 2\# & 3.15 & 2.92 & 2.57 & 2.30 & 3.11 & 3.08 & 3.02 & 2.92 & 2.97 \\
\hline
\end{tabular}

each individual intensive measure scheme was further simulated. The results are presented in Table 8. It can be seen that the strengthening water-saving scheme is the most effective one for improving water quality, and the three water-saving schemes of low, medium and high can reduce the $\mathrm{NH}_{3}-\mathrm{N}$ concentration of different indication sections by $7.3 \%-8.6 \%, 18.4 \%-21 \%$ and $27 \%-30.5 \%$, respectively. The water quality improvement effect of the ecological base flow protection scheme and the low scheme of drainage communication (with comprehensive degradation coefficient $\mathrm{k}$ increasing by $50 \%$ ) is basically the same, and the concentration of $\mathrm{NH}_{3}-\mathrm{N}$ in the lower reaches of the NCR will decrease by $1.4 \%$ $3.0 \%$. In addition, because the increased ecological base flow belongs to water bodies of Grade IV standard, the ecological base flow protection scheme also leads to a slight increase in $\mathrm{NH}_{3}-\mathrm{N}$ concentration in the U-WR belonging to the same grade of water function zone. The effect of improving water body fluidity is not obvious to reduce $\mathrm{NH}_{3}-\mathrm{N}$ concentration. According to the simulation results, when the comprehensive degradation coefficient $\mathrm{k}$ increases from $50 \%$ to $200 \%$, the concentration of $\mathrm{NH}_{3}-\mathrm{N}$ will be reduced by $0.12 \mathrm{mg} / \mathrm{L}$ in average. The scheme of ecological water replenishing can dramatically reduce the concentration of $\mathrm{NH}_{3}-\mathrm{N}$ in the Houweigou bridge section locating at the downstream of the water replenishment river reach. But the effect of water quality improvement for the lower reaches of the NCR is limited, which is not as good as that of the low domestic water-saving scheme. It is necessary to point out that any single intensive measure cannot make the $\mathrm{NH}_{3}-\mathrm{N}$ concentration of all indication sections achieve the water quality targets. And even adopting the most effective scheme of high water-saving, the simulated $\mathrm{NH}_{3}-\mathrm{N}$ concentration of the NCR 2\# section is still beyond the concentration limit of $2 \mathrm{mg} / \mathrm{L}$, with a gap of $0.3 \mathrm{mg} / \mathrm{L}$ to the water quality standard.

The water quality improvement effect of six combination enhancement schemes was then simulated, and the results are represented in Table 9. It is shown that through the implement of the three combination schemes on the basis of medium water-saving scheme, the concentration of $\mathrm{NH}_{3}-\mathrm{N}$ in the U-WR and L-WR as well as the upper reach of the NCR can achieve the water quality targets, but that of the lower reach of the NCR (after the Liangshui River converging) fail to meet the standard. When adopting the two scenarios of $\mathrm{v}$ and vi, the daily aver- 
age $\mathrm{NH}_{3}-\mathrm{N}$ concentration of all the indication sections can achieve the water quality targets. In the $\mathrm{v}$ program, the qualified days of the Tugou bridge, the Houweigou bridge and the NCR 1\#, 2\# sections increase to 360, 338, 304 and 207 days, respectively. The daily peak concentration of the NCR 2\# section dramatically drops to $3.73 \mathrm{mg} / \mathrm{L}$. In the vi program, the Tugou bridge section of standard days was unchanged, while the qualified days of Houweigou bridge section, the NCR $1 \#$ and 2\# increase to 365 days, 331 days, 231 days. The peak concentration of the four sections decreases to $1.93 \mathrm{mg} / \mathrm{L}, 1.99 \mathrm{mg} / \mathrm{L}, 2.27 \mathrm{mg} / \mathrm{L}$ and $3.73 \mathrm{mg} / \mathrm{L}$ respectively. Under the combined schemes of $\mathrm{v}$ and vi, the simulated $\mathrm{NH}_{3}-\mathrm{N}$ concentration curves of different indication sections are shown in Figure 6.

\section{Concluding Remarks}

The improvement of water environment quality is a serious challenge for Beijing's urban environmental planning and governance. In this paper, we propose a technical plan for the regulation of the main water pollutants in the Beijing North Canal River Basin. It is the first systematic study aiming at the long-term countermeasures for the improvement of water environment in this river basin. The research fully displays the arduous and long-term performance of the water environment quality improvement in the basin. There is no doubt that the

Table 9. The simulation results of $\mathrm{NH}_{3}-\mathrm{N}$ according to each combined intensive measure program. Unit, mg/L.

\begin{tabular}{|c|c|c|c|c|c|c|c|}
\hline \multirow{2}{*}{ Typical indication sites } & \multirow{2}{*}{$\begin{array}{l}\text { Medium population } \\
\text { regulation program(base) }\end{array}$} & \multicolumn{3}{|c|}{ Based on the medium water-saving scheme } & \multicolumn{3}{|c|}{ Based on the high water-saving scheme } \\
\hline & & Scheme i & Scheme ii & Scheme iii & Scheme iv & Scheme v & Scheme vi \\
\hline Tugou bridge & 1.52 & 1.16 & 1.16 & 1.16 & 1.03 & 1.03 & 1.03 \\
\hline Houweigou bridge & 2.10 & 1.44 & 1.57 & 1.44 & 1.37 & 1.37 & 1.31 \\
\hline NCR 1\# & 2.64 & 1.91 & 1.87 & 1.81 & 1.74 & 1.64 & 1.62 \\
\hline NCR 2\# & 3.15 & 2.36 & 2.25 & 2.19 & 2.14 & 1.98 & 1.96 \\
\hline
\end{tabular}

Note: The specific measures included in the combined scenarios i-vi presented in Table 9 are the same as that in section 3.3.2.
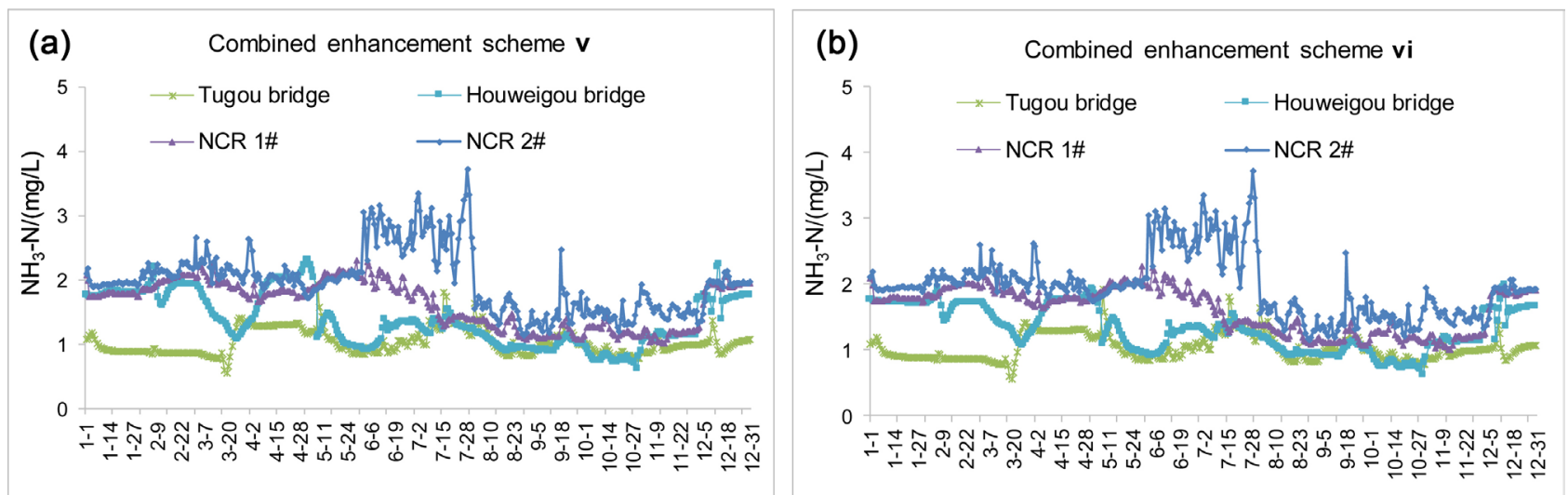

Figure 6. The simulated prediction results of $\mathrm{NH}_{3}-\mathrm{N}$ under the combined enhancement schemes $\mathrm{v}$ and vi. (a) $\mathrm{NH}-\mathrm{N}-\mathrm{Scheme} \mathrm{v}$; (b) $\mathrm{NH}_{3}$-N-Scheme vi. 
implement of the Action Plan for Prevention and Control of Water Pollution in Beijing is dramatically improving the surface water environment of the city. The concentration of the main water pollutants has been reduced by a large amount and the black and odorous water bodies have been basically eliminated. However, in order to achieve the water quality targets, intensive and combined measure programs should be further implemented.

Based on the evaluation results of water quality improvement effects under different scenarios, the strengthening water-saving scheme is highly recommended. It is especially important for the reduction of domestic water pollutant emission which accounts for the largest proportion of all kinds of pollution sources. Bearing in mind that the main source of water for the North Canal River is the urban sewage treatment plant drainage, the sewage treatment plants carry out the current local standard of DB 11/890-2012 requiring the drainage water to meet the standard value of Grade IV water bodies. As the target river belongs to the same grade or Grade $\mathrm{V}$ water function zones, which means there is almost no environmental capacity without considering the river's self-purification ability. Therefore, both the drainage communication scheme and ecological water replenishing scheme are highlighted to enhance the environmental capacity of river water bodies. When the total control requirements and measures are allocated to each sub-basin and administrative districts, they can be used as the basis for planning decision-making and governance assessment.

\section{Acknowledgements}

This work was supported by the National Natural Science Foundation of China under Grant [number 51809281 and 51509268] and the IWHR Research \& Development Support Program under Grant [number JZ0145B022017].

\section{Conflicts of Interest}

The authors declare no conflicts of interest regarding the publication of this paper.

\section{References}

[1] Ren, L., Cui, E. and Sun, H. (2014) Temporal and Spatial Variations in the Relationship between Urbanization and Water Quality. Environmental Science and Pollution Research, 23, 13646-13655. https://doi.org/10.1007/s11356-014-3242-8

[2] McGrane, S.J. (2016) Impacts of Urbanisation on Hydrological and Water Quality Dynamics, and Urban Water Management: A Review. Hydrological Sciences Journal, 13, 2295-2311. https://doi.org/10.1080/02626667.2015.1128084

[3] Yu, H., Song, Y., Chang, X., Gao, H. and Peng, J. (2018) A Scheme for a Sustainable Urban Water Environmental System during the Urbanization Process in China. Engineering, 2, 190-193. https://doi.org/10.1016/j.eng.2018.03.009

[4] Jia, H., Ma, H. and Wei, M. (2011) Calculation of the Minimum Ecological Water Requirement of an Urban River System and Its Deployment: A Case Study in Beijing Central Region. Ecological Modelling, 17, 3271-3276. 
https://doi.org/10.1016/j.ecolmodel.2011.05.026

[5] Marsalek, J., Karamouz, M., Cisneros, B.J., Malmquist, P.A., Goldenfum, J.A. and Chocat, B. (2014) Urban Water Cycle Processes and Interactions: Urban Water Series-UNESCO-IHP. CRC Press, Boca Raton. https://doi.org/10.1201/9781482288544

[6] Lian, J.J., Yang, Y. and Ma, C. (2017) Research Progress and Frontiers of Comprehensive Regulation of Urban River Network for Water Environment Improvement. Journal of Tianjin University (Science and Technology), 8, 781-787. (In Chinese)

[7] Kannel, P.R., Lee, S., Kanel, S.R., Khan, S.P. and Lee, Y.S. (2007) Spatial-Temporal Variation and Comparative Assessment of Water Qualities of Urban River System: A Case Study of the River Bagmati (Nepal). Environmental Monitoring and Assessment, 1-3, 433-459. https://doi.org/10.1007/s10661-006-9375-6

[8] Qin, H., Su, Q., Khu, S.T. and Tang, N. (2014) Water Quality Changes during Rapid Urbanization in the Shenzhen River Catchment: An Integrated View of Socio-Economic and Infrastructure Development. Sustainability, 10, 7433-7451. https://doi.org/10.3390/su6107433

[9] Lemos, D., Dias, A.C., Gabarrell, X. and Arroja, L. (2013) Environmental Assessment of an Urban Water System. Journal of Cleaner Production, 54, 157-165.

https://doi.org/10.1016/j.jclepro.2013.04.029

[10] Beale, D.J., Karpe, A.V., Ahmed, W., Cook, S., Morrison, P.D., Staley, C., Sadowsky, M.J. and Palombo, E.A. (2017) A Community Multi-Omics Approach towards the Assessment of Surface Water Quality in an Urban River System. International Journal of Environmental Research and Public Health, 3, 303. https://doi.org/10.3390/ijerph14030303

[11] Frey, S.K., Gottschall, N., Wilkes, G., Grégoire, D.S., Topp, E., Pintar, K.D.M., Sunoharaa, M., Marti, R. and Lapen, D.R. (2015) Rainfall-Induced Runoff from Exposed Streambed Sediments: An Important Source of Water Pollution. Journal of Environmental Quality, 1, 236-247. https://doi.org/10.2134/jeq2014.03.0122

[12] Cheng, P., Li, X., Su, J. and Hao, S. (2018) Recent Water Quality Trends in a Typical Semi-Arid River with a Sharp Decrease in Streamflow and Construction of Sewage Treatment Plants. Environmental Research Letters, 1, Article ID: 014026. https://doi.org/10.1088/1748-9326/aa9df2

[13] Zhu, Q.D., Sun, J.H., Hua, G.F., Wang, J.H. and Wang, H. (2015) Runoff Characteristics and Non-Point Source Pollution Analysis in the Taihu Lake Basin: A Case Study of the Town of Xueyan, China. Environmental Science and Pollution Research, 19, 15029-15036. https://doi.org/10.1007/s11356-015-4709-y

[14] Barnett, J., Rogers, S., Webber, M., Finlayson, B. and Wang, M. (2015) Sustainability: Transfer Project Cannot Meet China's Water Needs. Nature News, 527, 295-297. https://doi.org/10.1038/527295a

[15] United States Environmental Protection Agency (2002) Federal Water Pollution Control Act (33 U.S.C. 1251 et seq.). United States Government Publishing Office, Washington DC.

[16] Bulleit, K.A.N. (2000) Achieving Sustainable Development: A Review of the Environmental Balancing Act in Two Key Clean Water Act Regulatory Programs. Environmental Science \& Policy, 3, 15-20. https://doi.org/10.1016/S1462-9011(00)00089-7

[17] Alameddine, I., Qian, S.S. and Reckhow, K.H. (2011) A Bayesian Change Point-Threshold Model to Examine the Effect of TMDL Implementation on the Flow-Nitrogen Concentration Relationship in the Neuse River Basin. Water Research, 1, 51-62. https://doi.org/10.1016/j.watres.2010.08.003 
[18] Sigel, K., Klauer, B. and Pahl-Wostl, C. (2010) Conceptualising Uncertainty in Environmental Decision-Making: The Example of the EU Water Framework Directive. Ecological Economics, 69, 502-510. https://doi.org/10.1016/j.ecolecon.2009.11.012

[19] Graupner, B.J., Benthaus, F.C., Burger, S. and Werner, F. (2005) Implications of EU-Water Framework Directive for the East German Postmining Landscape Lausitz: Coping with a Sparse Knowledge of the Underground. Limnologica, 35, 199-205. https://doi.org/10.1016/j.limno.2005.06.004

[20] US Environmental Protection Agency Home Page. https://www.epa.gov/sites/production/files/2015-04/documents/cred_guidance_030 9.pdf

[21] Kannel, P.R., Kanel, S.R., Lee, S., Lee, Y.S. and Gan, T.Y. (2011) A Review of Public Domain Water Quality Models for Simulating Dissolved Oxygen in Rivers and Streams. Environmental Modeling \& Assessment, 2, 183-204. https://doi.org/10.1007/s10666-010-9235-1

[22] Wang, Q., Li, S., Jia, P., Qi, C. and Ding, F. (2013) A Review of Surface Water Quality Models. The Scientific World Journal, 2013, Article ID: 231768. https://doi.org/10.1155/2013/231768

[23] Zhao, Y.X., Zhao, C.P. and Chen, Y.A. (2016) Comparative Study of Regulatory Construction of the Watershed Environment Models System in China and Abroad. Environmental Pollution and Control, 7, 82-87. (In Chinese)

[24] Kamal, M.M., Malmgren-Hansen, A. and Badruzzaman, A.B.M. (1999) Assessment of Pollution of the River Buriganga, Bangladesh, Using a Water Quality Model. Water Science and Technology, 2, 129-136. https://doi.org/10.2166/wst.1999.0104

[25] Wu, Y.K., Lu, W., Ying, C., Shu, D. and Dong, H. (2011) Application of Numerical Simulation in Water Distribution for Water Quality Improvement. Journal of China Hydrology, 3, 56-59. (In Chinese)

[26] Doulgeris, C., Georgiou, P., Papadimos, D. and Papamichail, D. (2012) Ecosystem Approach to Water Resources Management Using the MIKE11 Modeling System in the Strymonas River and Lake Kerkini. Journal of Environmental Management, 1, 132-143. https://doi.org/10.1016/j.jenvman.2011.06.023

[27] Xiong, H.B., Chen, X. and Zhang, S.S. (2017) Method of Improving the Water Quality of Polluted Rivers Based on the MIKE11 Model. Environmental Science, 12, 5063-5073. (In Chinese)

[28] Nguyen, T.T., Keupers, I. and Willems, P. (2018) Conceptual River Water Quality Model with Flexible Model Structure. Environmental Modelling \& Software, 104, 102-117. https://doi.org/10.1016/j.envsoft.2018.03.014

[29] Chen, L., Dai, Y., Zhi, X., Xie, H. and Shen, Z. (2018) Quantifying Nonpoint Source Emissions and Their Water Quality Responses in a Complex Catchment: A Case Study of a Typical Urban-Rural Mixed Catchment. Journal of Hydrology, 559, 110-121. https://doi.org/10.1016/j.jhydrol.2018.02.034

[30] Cox, B.A. (2003) A Review of Currently Available In-Stream Water-Quality Models and Their Applicability for Simulating Dissolved Oxygen in Lowland Rivers. Science of the Total Environment, 314, 335-377. https://doi.org/10.1016/S0048-9697(03)00063-9

[31] Radwan, M., Willems, P. and Berlamont, J. (2004) Sensitivity and Uncertainty Analysis for River Water Quality Modelling. Journal of Hydroinformatics, 2, 83-99. https://doi.org/10.2166/hydro.2004.0008

[32] Olowe, K.O. (2018) Assessment of Some Existing Water Quality Models. Nature Environment and Pollution Technology, 3, 939-948. 
[33] Wang, Q.G., Dai, W.N., Zhao, X.H., Ding, F., Li, S.B. and Zhao, Y. (2009) Numerical Model of Thermal Discharge from Laibin Power Plant Based on Mike21FM. Research of Environmental Science, 3, 332-336. (In Chinese)

[34] Tian, Y., Liang, Y.P., Guo, J. and Jing, H.W. (2019) Analysis on Improvement Effect of Ten-Action Plan for Prevention and Control of Water Pollution on Surface Water in Beijing. Environmental Engineering, 4, 1-6. (In Chinese)

[35] The First National Pollution Census Data Compilation Committee (2011) Production and Excretion Coefficient Manual of Pollution Census Data. China Environmental Science Press, Beijing. (In Chinese)

[36] Pang, Y., Lu, G.H. and Wu, Z.Y. (2010) Theory and Application of Water Environment Capacity Calculation. Science Press, Beijing. (In Chinese)

[37] Johnes, P.J. (1996) Evaluation and Management of the Impact of Land Use Change on the Nitrogen and Phosphorus Load Delivered to Surface Waters: The Export Coefficient Modelling Approach. Journal of Hydrology, 3-4, 323-349. https://doi.org/10.1016/0022-1694(95)02951-6

[38] Ministry of Housing and Urban-Rural Development \& Ministry of Environmental Protection of the People's Republic of China (MOHURD and MOEP) Home Page. http://www.mohurd.gov.cn/wjfb/201509/t20150911_224828.html

[39] Wang, G., Qi, J., Pan, T., Song, X.S., Li, X. and Zhang, Y.P. (2016) Assessment of Emission Reduction Measures of the Main Pollutants in the North Canal River (Beijing Section). Environmental Pollution \& Control, 6, 39-45. (In Chinese) 